\title{
MINIMALLY INVASIVE CARDIAC SURGERY
}

\author{
Dhaliwal R.S.*
}

\section{ABSTRACT}

Conventional open heart surgery on cardiopulmonary bypass although safe and effective, but is associated with definite morbidity and mortality due to deleterious effects on body systems like haematological, renal, hepatic, respiratory and nervous system.

In the last two decades minimally invasive cardiac surgery is rapidly emerging as a safe and cost effective alternative therapeutic modality. The aims of minimally invasive cardiac surgery are to achieve an early extubation, less blood loss, rapid recovery, shorter hospital stay, less patient morbidity, faster return to routine activity, increased patient comfort and low cost without compromising on the results.

Various strategies have been developed to avoid cardio-pulmonary bypass, global myocardial ischemia and hypothermia. Minimally invasive cardiac surgery is especially beneficial in patients who are at high risk due to left ventricular dysfunction, calcified aorta, carotid artery occlusion, bleeding diathesis and impaired renal dysfunction

KEY WORDS: Congenital Heart \& Valvular Surgery, Valve Surgery, Coronary Artey Bypass Grafting.

* Professor, Department of Surgery, Universal College of Medical Sciences \&Teaching Hospital, Bhairahawa, Nepal

For correspondence:

Dr. R.S. Dhaliwal, M.S., M.N.A.M.S. (Surgery), M.Ch., D.N.B. (C.T.V. Surgery) F.A.C.S., F.C.C.P., F.A.M.S., F.N.C.C.P., F.I.C.A., F.I.A.C.S., Professor of Cardio Thoracic \& Vascular Surgery, Universal College of Medical Sciences \& Teaching Hospital, Bhairahawa, Nepal

E-mail: rsdhaliwal58@gmail.com 


\section{INTRODUCTION}

One of the most important discovery in cardiac surgery is the invention and successful use of techniques of Cardiopulmonary Bypass (CPB) for open heart surgery. ${ }^{1} \mathrm{At}$ present conventional open heart surgery on Cardiopulmonary Bypass (CPB) is both safe and effective but is associated with small but definite morbidity and mortality due to use of CPB. C-P Bypass causes activation of complement and neutrophils, microembolism and cerebral or renal dysfunction and global myocardial ischemia. In addition hypothermia and median sternotomy has its own problems.

Coronary endarterectomy and saphenous vein grafting were performed in the late 1950s on beating heart without using CPB. ${ }^{2}$ Kolesov from Russia reported the technique of mammary artery- coronary artery anastomosis on beating heart for treatment of coronary artery disease ${ }^{3}$. Later on Favaloro in U.S.A. popularised the technique of direct myocardial revascularisation by saphenous vein graft using CP Bypass ${ }^{4}$. In the early 1990s promising reports regarding coronary artery bypass without CPB were again presented Another major development was extension of minimally Invasive Surgery to the chest with the advent of VideoAssisted Thoracic Surgery (VATS)

New diagnostic and therapeutic strategies have rapidly developed and less invasive cardiac surgery is fast emerging as a safe and cost effective modality in patients who are at high operative risk for Cardio Pulmonary Bypass, like patients with left ventricle dysfunction, deranged renal functions, carotid occlusion, bleeding diathesis and calcified aorta.

The aim of minimally invasive cardiac surgery are early extubation, less blood loss, shorter hospital stay, less morbidity, more patient comfort, low cost and faster return to routine activity without compromising on the results of standard cardiac surgery. Minimal invasive cardiac surgery techniques have been developed for Coronary Artery Bypass Graft $(\mathrm{CABG})$, valve repair and replacement procedures and congenital heart diseases. ${ }^{6}$

\section{MINIMALLY INVASIVE CORONARY ARTERY BYPASS GRAFT SURGERY}

Several acronyms have been used to describe less invasive coronary bypass graft surgery. The most common is Minimally Invasive Direct Coronary Bypass Graft (MIDCABG) used for Left Internal Mammary Artery (LIMA) to Left Anterior Descending Artery (LAD) grafting on beating heart without cardiopulmonary bypass through a left anterior mini thoracotomy. Others include Minimally Invasive Coronary Surgery (MICS), Minimally Invasive Coronary Artery Surgery (MICAS) and OffPump Coronary Artery Bypass (OPCAB).
The term 'Port access' is used for a procedure performed through a limited anterior thoracotomy where cardiopulmonary bypass is employed from femoro-femoral approach. The currently available options for coronary bypass graft surgery with their advantages and disadvantages are shown-

Table 1: Surgical Options for CABG

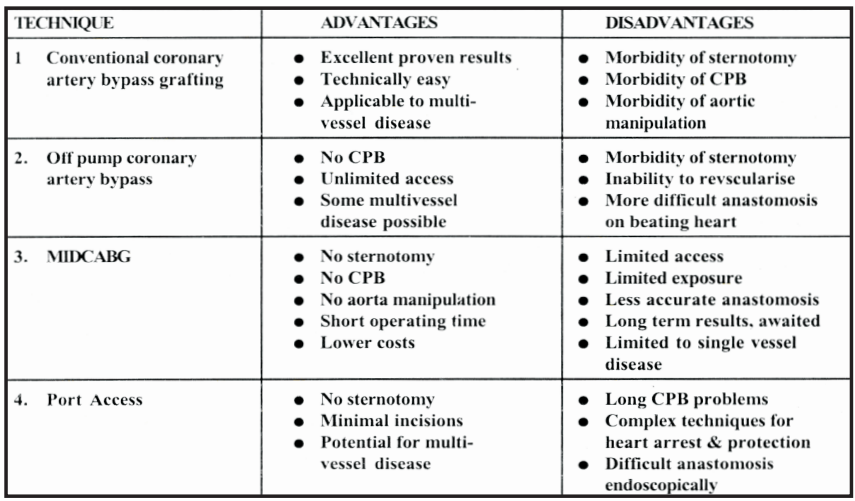

INDICATIONS for $\mathrm{MIDCABG}^{7}$ The indications for MIDCABG are evolving and subject to change depending on experience of the operating team. Following are the currently accepted indications:

1. Isolated LAD or right coronary (RCA) lesion or both, where PTCA is not advisable due to complex stenosis or complete occlusion

2. Proximal LAD or RCA lesion or both

3. Re-operation for single graft to LAD with prior saphenous vein great occlusion

4. Where CPB has a possible high mortality ie peripheral vascular disease, cerebrovascular accidents, COPD, renal failure, aortic atherosclerosis

5. Re-stenosis after PTCA

The evolving indications for MIDCABG are:

1. LIMA to LAD along with PTCA to other vessels Hybrid procedures

2. LIMA to LAD as an adjunct to major non cardiac procedures e.g. abdominal aortic aneurysm repair

3. Ischemic cardiomyopathy with anterior wall ischemia (LAD area)

The ideal anatomic conditions for MIDCABG are:

1. LAD size more than $2 \mathrm{~mm}$

2. Tubular heart on X-ray chest

3. Thin chest wall with wide intercostal spaces

4. Reoperative coronary artery bypass due to blocking saphenous vein graft

5. Non calcified LAD

6. Totally occluded LAD with good collaterals to distal LAD

7. Left ventricular dysfunction 
The relative contraindications for MIDCABG are:

1. Intra-myocardial LAD

2. Diffusely calcified LAD

3. Large left ventricle

4. Severe pulmonary hypertension

In these conditions MIDCABG becomes technically more difficult and complications like bleeding, hypotension, arrhythmias and high rate of graft occlusion are more common. More recently MIDCABG has been used for mid and distal RCA, Posterior Descending Artery (PDA) and circumflex marginal arteries via right anterior thoracotomy, subxiphoid approach or short left lateral thoracotomy .Total arterial revascularisation can be done using both internal mammary arteries, right gastroepiploic and radial artery as conduits

\section{SURGICAL TECHNIQUES ${ }^{8,9}$}

Anaesthesia is induced with Fentanyl and Sodium pentothal and maintained with Fentanyl. Pancuronium bromide provides muscle relaxation and in final stage of surgery, a mixture of nitrous oxide and oxygen is used to allow rapid awakening.

Minimal access approach was started with LIMA to LAD graft through a $10 \mathrm{cms}$ transverse incision over the left fourth costal cartilage. However, midsternotomy provides unparallel access to LAD and RCA with remarkably little morbidity and it is the least painful thoracic surgical incision .Partial lower sternotomy can provide sufficient access for LIMA to LAD or right internal mammary artery to RCA grafting. Various surgical approaches to harvest IMA in minimally invasive $\mathrm{CABG}$ and their various advantages and disadvantages have been shown in Table 2. Isolation of a long segment of LIMA is essential to avoid kinking, allow tension free anastomosis and deviate the concern of coronary steal

Table 2: Surgical Techniques for coronory artery bypass grafting

\begin{tabular}{|c|c|c|}
\hline TYPE OF INCISION & ADVANTAGES & DISADVANTAGES \\
\hline $\begin{array}{l}\text { 1. Anterio-vertical mini } \\
\text { thoracotomy- cartilages } \\
\text { excised }\end{array}$ & $\begin{array}{l}\text { Direct exposure of IMA } \\
\text { - Exposure from 2nd to 6th } \\
\text { intercostal spaces }\end{array}$ & $\begin{array}{l}\text { Chronic chest pain } \\
\text { - Lung bulging/ hernia }\end{array}$ \\
\hline $\begin{array}{l}\text { 2. Left anterior small } \\
\text { thoracotomy (LAST) }\end{array}$ & $\begin{array}{l}\text { Lateral exposure to LIMA } \\
\text { No rib or cartilage excision } \\
\text { - LIMA harvesting possible } \\
\text { from 2nd to } 6 \text { th ribs }\end{array}$ & $\begin{array}{l}\text { - Pain due to rib fracture } \\
\text { - Variable access to } \\
\text { proximal LAD }\end{array}$ \\
\hline 3. Mini-sternotomy & $\begin{array}{l}\text { - Access to entire LAD } \\
\text { - Good access to both IMA }\end{array}$ & $\begin{array}{l}\text { - Sternal infection and } \\
\text { nonunion } \\
\text { - Increased risk at reoperation }\end{array}$ \\
\hline 4. Parasternal incision & $\begin{array}{l}\text { - Good access to mid and } \\
\text { distal LAD }\end{array}$ & $\begin{array}{l}- \text { Chronic chest pain } \\
\text { - Poor cosmetic results }\end{array}$ \\
\hline $\begin{array}{l}\text { 5. Video assisted thoraco- } \\
\text { scopic surgery (VATS) }\end{array}$ & $\begin{array}{l}\text { - Complete IMA mobilisation } \\
\text { up to its origin }\end{array}$ & $\begin{array}{l}\text { More operative time } \\
\text { Technically more demanding } \\
\text { - Requires experience in } \\
\text { endoscopy } \\
\text { - Needs additional incision } \\
\text { for anastomosis }\end{array}$ \\
\hline
\end{tabular}

Ischemic preconditioning is done by repeated short occlusions of the LAD using 4-0 prolene suture passed around LAD as snares. The snare is tightened to ensure a bloodless operative field. The technique of coronary artery anastomosis on beating heart is technically demanding. Partial immobilisation of target coronary artery site is done by inducing bradycardia (40-50 beats/minute) using drugs like adenosine or beta blockers (esmolol) or calcium channel blockers i.e. diltiazem or verapamil. The artery is further stabilize using immobilisation devices like octopus device or starfish device. LAD is opened for $5-6 \mathrm{~mm}$ and anastomosed to LIMA using 7 or 8-0 prolene.

The patients are either extubated in the operation theatre or after some time in the ICU. The flow pattern in the graft can be assessed by continuous wave Doppler echocardiography. The chest drains are removed after $24 \mathrm{hrs}$ and patient can be discharged within 48-72 hrs.

Arterial pulse counter analyser which calculates cardiac output and hemodynamic based on continuous arterial pulse counter analysis is a reliable and less invasive monitoring tool during minimally invasive coronary surgery. The patients have lower pain levels from third day onwards and early mobilisation is possible. The quality of anastomosis depends on the experience of the surgeon. The long term patency of the graft performed on beating heart in comparison to the standard CABG on bypass is still debatable.

The port access technology ${ }^{10}$ enables the surgeons to perform various open heart procedures including CABG and valve procedures less invasively using cardiopulmonary bypass from peripheral vessels. An endovascular clamp is used to produce endovascular aortic occlusion, cardioplegia delivery and left ventricular decompression. Antegrade carioplegia is delivered through a central lumen, which also acts as an aortic root vent. A second lumen is used for aortic root pressure monitoring and the third lumen for balloon inflation to provide aortic occlusion. The arrested heart allows for better exposure of lateral and posterior aspect of the heart and permits rotation of the heart to fully expose the three coronary vessels.

\section{MINIMALLY INVASIVE VALVE SURGERY}

Minimally invasive valve surgery is even more challenging than coronary procedures. Carpentier from Paris ${ }^{11}$ performed the first video assisted mitral valve repair through a minithoracotomy incision in 1996. In the same year Stanford group from USA performed the first minimally invasive mitral valve replacement using 'port access' technology. Various minimal access incisions have been proposed to reduce the related surgical trauma.

Patient selection ${ }^{12}$ : This technique is not used in very obese patients or those with chest wall deformities (pectus excavatum or deep anteroposterior diameter ) and those with 
unusual cardiac orientation. Associated significant multivessel coronary artery disease is a contraindication to minimally invasive valve surgery.

Surgical approach: Cosgrove used right parasternal incision for minimal invasive valve surgery with good results ${ }^{13}$. Right anterolateral minithoracotomy and the subxiphoid approach have been used successfully. Various other approaches have been used for this like transverse sternotomy, inverted $\mathrm{T}$, reversed L or J ministernotomy, superior hemisternotomy and parasternal incisions. The relationship of heart valve to the surface anatomy of the chest needs to be considered for the most suitable approach. ${ }^{14}$

Cannulation: For conventional $\mathrm{CPB}$, right atrium and ascending aorta are cannulated. In many techniques transfemoral cannulation is done but groin incisions are prone to more complications like pain, infection and lymph drainage. Femoral cannulation may be hazardous in patients with atherosclerosis and there is always a possibility of retrograde dissection of femoral artery, ischemic complications and delayed wound healing. Right femoral vein and superior vena cava cannulation for venous drainage and aortic cannulation for arterial return is popular method. Use of transthoracic aortic clamp in place of endoaortic clamp is preferred.

Port access valve surgery can be performed using Endo Cardiopulmonary bypass using five endocatheters. ${ }^{1.5}$

1. An endoaortic ballon tip catheter placed in ascending aorta

2. An endopulmonary vent

3. An endocoronary sinus catheter for retrograde cardioplegia

4. An endoarterial return canula placed in femoral artery

5. Endovenous drainage catheter placed in femoral vein

Transesophageal echocardiography(TEE) is used to guide cannulation, remove intracardiac air and assess the results of surgery. The technical aspects of minimal invasive surgery are similar to conventional valve surgery but are more difficult due to limited space. Tying knots especially anterior annulus sutures can be tedious. Special efficient suture holders and instruments are needed to facilitate the procedure.

In addition, three dimensional video can restore some of the visual prospective lost in such a deep operative field. Minimally invasive valvular operations require a significant longer (upto $40 \%$ more) CPB time. These patients may develop post operative atrial fibrillations $(20 \%)$ and groin complications ( $8 \%$ ) and almost half of the patients may still require post operative blood transfusion.

Although minimally invasive valve surgery may reduce ICU stay, lower blood transfusion requirement, decreased operative discomfort, improve cosmetic results and provide early rehabilitation, the question whether a smaller incision is worth a longer CPB time, is still debatable. Therefore, surgeons should adopt an operative procedure according to the patient's needs and never compromise on clinical outcome ${ }^{15}$.

\section{MINIMALLY INVASIVE CONGENITAL CARDIAC SURGERY}

Video assisted ligation of patent ductus is a common operation under minimally invasive category. Patient is placed in right lateral decubitus position and four trocars are placed through small incisions. The medial port admits grasping forceps, next port admits expanding lung retractor, next is for videoscope and posterior is for cautery and clip applicator. The left upper lobe is retracted medially using the expanding lung retractor. The left subclavian artery take off is used for orientation. Parieal pleura over the ductus is incised with cautery and ductus is clamped with endoscopic clip using applicator. If required the procedure can be converted into an open procedure by simply by joining the incisions for trocar ports incisions ${ }^{16}$.

Various minimal approaches are now used to improve the cosmetic results especially in younger female patients having atrial septal defects (ASD)The following techniques are commonly used for ASD closure using minimally invasive methods

1. Right parasternal mini incision, aortic and central venous cannulation

2. Rirght submammary mini incision, femoral arterial and central venous cannulation

3. Right submammary mini incision, femorl artery, right atrial and percutaneous jugular vein cannulation.

4. Port access technology

The right parasternal incision is asymmetrical and easily visible, therefore, now right submammary mini incision is preferable as it is better cosmetically and avoids internal mammary artery injury. Transesophageal echocardiography (TEE) is used for checking adequate results and de-airing of the heart

\section{CONCLUSION}

Minimally invasive cardiac surgery has definite advantages over standard operations like less surgical trauma, less pain, better cosmetic results and avoidance of CP Bypass. There is less blood loss, less post operative ventilation, shorter hospital stay, rapid recovery and less cost. This author has used minimal invasive techniques for cardiac surgery since 1997 and was one of first cardiac surgeon to start these new techniques in India. Minimal invasive techniques were used for valve replacements, congenital heart surgery and coronary artery bypass grafting. Partial sternotomy (J or inverted T ) and small right anterolateral thoracotomy were the main approaches. Standard CPB was used, cannulation of SVC and IVC for venous return and aorta for arterial return was done. There was no mortality in 500 pts operated upon over more 
than a decade. No technical difficulty was encountered. The post operative blood loss, ventilation time and ICU stay were considerably less. The patient recovery was quicker and post operative pain less. In case of ASD in younger females, right submammary small thoracotomy was used .Apart from the benefits mentioned above these patients were quite happy with the better cosmetic scars.

\section{FUTURE PROSPECTS}

Carpentier and associates in May 1998 performed the first robotic cardiac surgery with closure of atrial septal defect and mitral valve repair ${ }^{18}$. In this technique, advanced computer technology is used for direct translation of digitalized data of surgon's hand movements who acts as master console(control). This data is guiding the fine mechanical and precise motion of the robot placed near the patient's chest performing the operation ${ }^{19}$. Robotic assisted instruments have made endoscopic coronary bypass possible and has opened a new era in minimally invasive surgery. Da Vinci robotic system for MIDCABG is becoming quite popular in the western countries. ${ }^{20,21}$

\section{REFERENCES}

1. Kirklin JW, DuShane JW, Patrik RT. Intra cardiac surgery with the aid of a mechanical pump oxygenator system (Gibbon type). Report of eight cases.Proc Staff Mayo Clinic 1955, 30:201-9

2. Murray G, Porcharaon R, Hilario J,Rochlay W. Anastomosis of systemic artery to coronary artery. Can Med Assoc.Jr 1954; 71; 594-7

3. Kolesov VI. Mammary artery coronary artery anastomosis as a method for treating angina pectoris. Jr Thorac Cariovasc Surg1967,54: 535-44

4. Favaloro $R G$, Effler $D B$, Groves $L K$, Sheldon $W C$, Sones $F M$. Direct myocardial revascularisation by saphenous vein graft.Present operative techniques and indications Ann. Thorac.Surg 1970; 10: 97-111

5. Benneti FJ, Naselli G, Wood M, Geffner L. Direct myocardial revascularisation with extra corporeal circulation. Experience in 700 patients. Chest 1991; 100: 312-16

6. Balaquer JM, Umakanthan $R$, Leacche $M$, Byrne JG Minimally invasive cardiac surgery. Curr Probl Surg. 2012, 49(9), 529-49

7 Subramaniam VA. Less invasive arterial CABG on beating heart. Ann. Thorac. Surg1997; 63:868-71
8. Westabt S, Benetti FJ. Less invasive coronary surgery Consensus from the Oxford meeting. Ann. Thorac. Surg.1991-6396; 62: 924-31

9. Calafiore AM, Angelini GD. Left anterior small thoracotomy (LAST) for coronary artery revascularisation surgery 1997; 12: 61-63

10. Sellke FW, Chu LM, Cohen WE. Current state of surgical myocardial revascularization.. Circ Jr. 2010 74(6):1031-7

11. Pann JI, Pompli MF, Slevens JH, Siegel LC et al. Port access cardiac operations with cardioplegia arrest. Ann Thorac.Surg 1997; 63:535-39

12. Carpentier A, Loulone D. Open heart operation under video surgery using mini thoracotomy. First case (mitral valvuloplasty) operated with success. CR Acad Sci III 1996;319(3): 219-23

13. Aklog L, Adams DH, Couper GS. Cohen LH et al. Techniques and results of direct access minimally invasive mitral valve surgery; A paradigm for the future. Jr Thorac Cardiovasc. Surg 1998; 116: 705-15

14 Cosgrove DM, Sabik JF, Nara JL. Minimally invasive valve operations. Ann Thorac. Surg 1998;54: 1535-39

15. Reardon MJ,Conklin LD, Philo $R$,Espada $R$ et al. The anatomical aspects of minimally invasive cardiac valve operations. Ann Thorac. Surg. 1999; 67: 266-68

16. Arom KV, Emery RW, Kshetty VR, Jancy PA. Comparison between port access and less invasive valve surgry .Ann.Thorac. Surg. 1999; 68:1525-28

17. Burke RP. Patent ductus arteriosus. In Kaiser LR, Kron IL, Spray TC. Mastery of Cardiothoracic Surgery. Lippen Cort Ravemern 1998; 10:92-104

18. Cremer JT, Boning A, Ansari MB, Kirn PY et al. Different approaches for minimally invasive closure of atrial septal defects. Ann Thorac.Surg. 1999; 67:1648-52

19. Carpentier A, Loulmet D, Aupeck B, Keiffer $J$ et al. Computer assisted open heart surgery: First case operated on with success. CR Acad Sci III 1998; 321: 437-42

20. Chitwood WR Jr. Endoscopic Robotic coronary surgery, is this reality or fantasy? Jr Thorac Cardiovasc. Surg 1999; 118(1): 1-3

21. Loumet D, Carpentier A, Attellis N, Berrebi A et al. Endoscopic coronary artery bypass grafting with the aid of Robotic assisted instruments. Jr Thorac, Cardiovasc.Surg 1999; 118(1): 4-10

22. Magee MJ, Mack MJ. Robotics and coronary artery surgery, Review Curr Opin Cardiol. $2002 ; 17(6): 602-7$. 